\title{
O DISCURSO JURÍDICO E O CONTROLE BIOPOLÍTICO DOS CORPOS DAS MULHERES TRABALHADORAS: DA PEC 181-A A REFORMA TRABALHISTA
}

\section{Luciana Alves Dombkowitsh ${ }^{1}$}

\section{RESUMO}

Este estudo problematiza o discurso jurídico sobre os corpos das mulheres e a diferencial distribuição da precariedade em suas vidas, partindo da PEC 181-A, que propõe a proteção da vida desde a concepção, interferindo nas regras de abortamento legal no Brasil e do artigo 394-A da CLT, que retira proteção à maternidade. Esses discursos biopolíticos produzem enquadramentos definindo quais vidas são relevantes para o direito. Utilizou-se abordagem qualitativa enfatizando os estudos culturais feministas. Esta investigação pretende avançar nos estudos de gênero, como urgentes demandas que se encontram nos corpos de mulheres, cuja invisibilidade e silêncio se perpetuam histórica e socialmente.

Palavras-chave: aborto; maternidade; precariedade; gênero; mulher

\section{HE LEGAL SPEECH AND THE BIOPOLITICAL CONTROL OF THE BODIES OF THE WORKING WOMEN: FROM PEC 181-A THE LABOR REFORM}

\begin{abstract}
This study questions the legal discourse on the bodies of women and the differential distribution of precariousness in their lives, starting from PEC 181-A, which proposes the protection of life from conception, interfering with the legal abortion rules in Brazil and article 394 -A of the CLT, which removes maternity protection. These biopolitical discourses produce frameworks defining which lives are relevant to the law. We used a qualitative approach emphasizing feminist cultural studies. This research intends to advance gender studies as urgent demands that are found in the bodies of women whose invisibility and silence are perpetuated historically and socially.
\end{abstract}

Keywords: abortion; maternity; precariousness; genre; woman

\section{INTRODUÇÃO}

Este estudo tem como objetivo problematizar o discurso jurídico sobre os corpos das mulheres e a diferencial distribuição da precariedade em suas vidas, tendo como ponto de partida o relatório final da comissão especial destinada a proferir parecer à proposta de emenda à constituição n. ${ }^{\circ} 181-\mathrm{A}$, de 2015 , do senado federal, que originalmente propunha a alteração do inciso XVIII do artigo $7^{\circ}$ da Constituição Federal para dispor sobre licençamaternidade em caso de parto prematuro e a sua intersecção com a Lei 13.467/17, que alterou o artigo 394-A da CLT.

O referido parecer foi aprovado no dia 08/11/2017 com 18 votos a favor e um contrário, em flagrante desvio de objeto posto que aprova ao final, além da alteração do inciso

\footnotetext{
${ }^{1}$ Mestre em direito e justiça social pela FURG. Realiza disciplina como aluna especial no programa de doutorado em educação da UFPEL. Professora de Direito na Faculdade Anhanguera do Rio Grande. Pesquisadora na área de gênero e sexualidades. E-mail: lucianadomb@ vetorial.net.
} 
XVIII do artigo $7^{\circ}$, a alteração do inciso III do artigo 1 e o caput do artigo $5^{\circ}$, ambos da Constituição Federal, introduzindo ao texto a proteção da vida e da dignidade humana desde a concepção, interferindo na interpretação de todas as leis e portarias que autorizam hoje serviços de abortamento legal no Brasil.

No entanto, se faz necessário analisar de que forma o texto do parecer da PEC 181-A, aprovado em 08/11/2017 se relaciona com o artigo 394-A alterado pela Lei 13.467/17, aprovada em 14/07/2017 e que entrou em vigor três dias após a aprovação do referido parecer. É preciso identificar quais os enquadramentos produzidos por estes textos que são capazes de definir quais vidas são relevantes para o direito a partir de uma perspectiva de quais vidas merecem ser vividas.

A redação original do artigo 394-A da CLT garantia que a empregada gestante ou lactante fosse afastada, enquanto durasse a gestação e a lactação, de quaisquer atividades, operações ou locais insalubres, não fazendo qualquer distinção quanto aos graus de insalubridade, garantindo que o exercício de suas atividades se desse em local sadio. $\mathrm{O}$ artigo 384-A demonstrava a sintonia entre a legislação trabalhista e o direito fundamental de proteção à maternidade e à infância, previsto no artigo $6^{\circ}$ da Constituição Federal.

No entanto, o referido artigo foi brutalmente transmudado pelo legislador reformista, retirando a proteção social da gestante e da lactante submetendo-a a insalubridade no meio laboral. As alterações introduzidas no artigo 394-A, trazem condições variáveis quanto ao trabalho da gestante em condições insalubres, já que, excetuando a insalubridade em grau máximo, a gestante apenas poderá se afastar das demais atividades insalubres se apresentar atestado médico. A lactante por sua vez, terá que apresentar atestado médico para se afastar de ambiente insalubre de qualquer grau.

O parecer da PEC 181-A que introduz a proteção à vida e a dignidade da pessoa humana desde a concepção, propondo a alteração do inciso III do artigo $3^{\circ}$ e do caput do artigo $5^{\circ}$ da Constituição Federal serve exclusivamente para impor, através do discurso jurídico, um maior controle biopolítico sobre os corpos das mulheres. A alteração do artigo 394-A demonstra que o legislador pátrio não está preocupado com a vida do embrião ou do nascituro, haja vista que autoriza o trabalho tanto da gestante quanto da lactante em locais insalubres, colocando em risco a vida de ambos.

Protege-se a vida desde a concepção para se impor controle sobre os corpos das mulheres, em negação a sua própria autonomia, ao mesmo tempo em que se autoriza o trabalho de gestantes e lactantes em condições insalubres. A relação entre a PEC 181-A e a nova redação do artigo 394-A da CLT dá o tom da intensificação dos ataques aos direitos das mulheres e neste particular ao direito das mulheres trabalhadoras.

$\mathrm{O}$ atual contexto legislativo brasileiro possibilita a abordagem de questões absolutamente contemporâneas ao cotidiano da mulher brasileira, marcada pela subordinação, dependência, desigualdade nas relações laborais, negação da sua sexualidade e do desejo, mas, sobretudo, expõe a face mais perversa de um modelo de sociedade neoliberal, que agravada pelos conflitos de classe, gêneros, raças e sexualidades, precariza vidas de mulheres em espaços urbanos e rurais violentos, segregando-as e subalternizando-as em modelos de espoliação laboral-corporal. 
Para esta investigação, utilizou-se de abordagem qualitativa com ênfase nos estudos culturais feministas de Butler $(2014$; 2015), Lagarde (2015) e Spivak (2010). Ancora-se ainda, nos apontamentos de Foucault $(2014 ; 2015)$, nas discussões sobre direitos humanos de Escrivão Filho e Sousa Júnior (2016) e nos debates em direito do trabalho de Delgado e Delgado (2016), Martinez (2018) e Maior e Severo (2017).

Propõe-se, como estrutura desta investigação, analisar o relatório aprovado na comissão especial destinada a proferir parecer à proposta de emenda à constituição n. $^{\circ} 181-\mathrm{A}$, o seu impacto nas formas legais de realização de aborto no Brasil, o seu papel biopolítico e o contra censo em relação a nova redação do artigo 394-A introduzido pela Lei 13.467/17. Diante destas abordagens, pretende verificar a proteção à maternidade prevista na legislação trabalhista brasileira antes da reforma trabalhista, especialmente no que se refere aos aspectos relacionados a gestação e a lactação.

A partir destas duas questões se propõe analisar as relações imbicadas entre o discurso jurídico e o controle biopolítico dos corpos das mulheres, em especial das mulheres trabalhadoras dentro de um contexto que aborde tanto as relações de trabalho como a violência de gênero sob uma perspectiva de direitos humanos, dando-se posterior ênfase às relações de subalternidade das mulheres em um mundo do trabalho violento e precarizante.

Para além de problematizar a subalternidade das relações de trabalho e das violências de gênero perpetradas tanto no mundo do trabalho como nos corpos das mulheres, este estudo pretende problematizar a diferencial distribuição da precariedade na vida das mulheres, se propondo ainda, avançar nos debates sobre estudos de gênero, cuja ênfase se enquadra no campo das desigualdades e déficits de reconhecimento.

Espera-se que estes diálogos aqui apresentados, sirvam como elementos potencializadores e de desvelamento das urgentes demandas que se encontram nos corpos, nas vidas e narrativas de milhares de mulheres brasileiras, cuja invisibilidade e o silêncio se perpetuam histórica e socialmente.

\subsection{DIREITO À VIDA DESDE A CONCEPÇÃO NA PEC 181-A: QUAIS ENQUADRAMENTOS ESTABALECEM AS VIDAS QUE MERECEM SER VIVIDAS?}

A proposta de emenda à Constituição n. ${ }^{\circ}$ 181-A, originária PEC 181 do Senado Federal, foi apresentada em dezembro de 2015 com a proposta de alterar a redação do inciso XVIII do art. $7^{\circ}$ do texto constitucional para ali inserir menção à possibilidade de, em caso de parto prematuro, a licença-maternidade estender-se pelo período de internação do recémnascido, observado o limite máximo de duzentos e quarenta dias.

Após aprovação na Comissão de Constituição e Justiça da Câmara de Deputados, foi criada comissão especial para proferir parecer à proposta de emenda à constituição n. ${ }^{\circ}$ 181-A apensada a PEC 181/2015 e à PEC 58/2011, todas tratando da mesma questão. Ocorre que esta referida comissão, a partir de um substitutivo apresentado pelo relator Jorge Tadeu Mudalen, aprova por ampla maioria um parecer que, além de propor a alteração no inciso XVIII do artigo $7 .^{\circ}$ da $\mathrm{CF}$, retirando apenas o limite de duzentos e quarenta dias, propõe alterar o inciso III do artigo $1 .^{\circ}$ e o caput do artigo $5 .^{\circ}$ da Constituição Federal. 
Para além de todo debate de afronta a técnica legislativa, o referido parecer foi aprovado com o voto de dezoito deputados homens, tendo apenas um voto contrário dado pela única mulher da comissão. A comissão, que é majoritariamente formada por homens, os quais ao final da votação comemoraram o resultado entoando em coro "vida sim, aborto não", decidiu por uma emenda à constituição federal que interfere na interpretação de todas as leis e portarias que autorizam hoje serviços de abortamento legal no Brasil.

$\mathrm{Na}$ fundamentação dada no parecer pelo relator, este aduz que a Constituição Federal deverá dar proteção especial não somente aquele que nasce prematuramente, mas inclusive aquele que se encontra no âmbito uterino, desde seu início, isto é, desde a concepção:

Diante do exposto, cabe-nos observar que se protegemos, de forma justíssima, aquele que já vivia e prematuramente deixou a proteção materna, concedendo uma ampliação da licença maternidade à sua genitora, não podemos deixar de explicitar, ainda mais, a sua proteção no âmbito uterino, desde o seu início, isto é, desde a concepção.(BRASIL, 2018)

Conforme se pode depreender do parecer da comissão especial, este se caracteriza como uma espécie de repúdio ao dito "ativismo judicial, o qual decorre especialmente da decisão de 2016 proferida pela $1 .^{\text {a }}$ Turma do Supremo Tribunal Federal ${ }^{2}$, que declarou não ser crime a prática do aborto durante o primeiro trimestre de gestação, independentemente da motivação da mulher:

No caso específico do aborto, assunto complexo e sensível, a sede própria para a sua
discussão é, indiscutivelmente, o Poder Legislativo e não o Supremo Tribunal
Federal, seja como colegiado, seja sobretudo em suas turmas ou considerando-se os
seus membros isoladamente. Ao Tribunal falta competência e legitimação
constitucional para definir o tema de tal importância. (BRASIL, 2018)

Assim, após a aprovação do substitutivo do relator, o parecer da comissão especial propôs alteração na redação do inciso III do artigo $1^{\circ}$ da Constituição, que trata dos princípios fundamentais da República, inserindo a frase: "dignidade da pessoa humana desde a concepção". Também no caput do artigo $5^{\circ}$ - o que garante a igualdade de todos perante a lei e a inviolabilidade do direito à vida - acrescentando a expressão "a inviolabilidade do direito à vida desde a concepção".

Consequentemente, no que se refere a hierarquia das leis, tem-se que a Constituição Federal está no topo e por esta razão, a mudança proposta pelo parecer afetará, necessariamente, toda a interpretação infraconstitucional a respeito do que se tem atualmente regrado a cerca das possibilidades legais de aborto. Essa mudança, como se verá no capítulo seguinte, em nada tem a ver com a tão propagada preocupação com a proteção da vida desde a sua concepção e sim, em impor um rígido controle sobre os corpos das mulheres, lhes retirando autonomia e o direito à emancipação.

Dos fundamentos utilizados pelo relatório, um merece destaque especial, o qual, segundo o relator, foi retirado da fala de Lilia Nunes dos Santos, ouvida durante as audiências públicas, a qual "[...]observou não existir um direito absoluto à liberdade (da mulher) ao ponto de suprimir o direito à vida do nascituro." Segue ainda, "[...] todo direito fundamental

${ }^{2}$ Habeas Corpus 124.306 do STF

Revista de Gênero, Sexualidade e Direito| e-ISSN: 2525-9849 | Salvador | v. 4 | n. 1 | p. 156 - 170 | Jan/Jun. 
tem um limite, e na ponderação entre princípios - método hermenêutico tão aplicado em nossos tempos -, não há margem para a prevalência de um pela supressão do outro."

Nesta linha, considera inadmissível a ideia de tornar absoluta a liberdade de escolha da mulher ao aborto como direito fundamental. Este dilema, entre quais vidas devem ser preservadas e quais podem ser desperdiçadas, se torna relevante a discussão a cerca de que vidas merecem ser vividas. Para Butler (2015), é essencial que se saiba o que é uma vida e que esta vida é construída por meios seletivos, tornando-se, portanto, além de um problema político, de um problema epistemológico.

Quanto aos meios seletivos, Butler (2015) vai dizer que se tratam das relações de poder existentes na sociedade as quais se constituem nos mecanismos específicos onde a vida é produzida. Para a autora, as molduras ou enquadramentos pelos quais se apreende a vida dos outros como perdidas ou lesadas, ou melhor, como não se apreende, estão politicamente esgotadas. Butler (2015) defende a necessidade de uma nova ontologia corporal que repense a precariedade, a vulnerabilidade e a dor suportada por esses mesmos corpos. No entanto, esta nova ontologia do corpo não tem como ser repensada senão a partir também dos discursos que organizam social e politicamente a sociedade.

As molduras pelas quais se apreendem a vida das mulheres estão marcadas pela desigualdade nas relações sociais, pautada pela subordinação, dependência, negação da sua sexualidade e do seu desejo. Mas, sobretudo, estão expostas à face mais perversa de um modelo de sociedade neoliberal que, agravado pelos conflitos de classe, gênero, raça e sexualidade, precariza a vida de mulheres em espaços urbanos violentos, segregando-as e subalternizando-as em modelos de espoliação laboral-corporal. O discurso jurídico, ao seu tempo, potencializa essa precariedade. Torna-se, portanto, crucial discutir a categoria corpo e problematizar de que forma este favorece o controle das mulheres na sociedade.

\section{A REFORMA TRABALHISTA IMPOSTA AO ARTIGO 394-A E A RETIRADA DA PROTEÇÃO À MATERNIDADE - DESDE A GESTAÇÃO ATÉ A LACTAÇÃO}

O mundo do trabalho é um dos campos sociais que expõe e maximiza a precariedade na vida das mulheres. Neste sentido, considera-se importante falar do Trabalho através da obra da autora Hannah Arendt (2015), A Condição Humana. Na obra ela diferencia as três atividades do homem: o trabalho (manutenção da vida); a obra (produção de algo novo); e a ação (vida pública, política). Estas três atividades fazem parte do que a autora denominou de vitaactiva: a vida humana.

Para Arendt (2015), historicamente, o trabalho era considerado apenas o resultado da luta do homem contra as suas necessidades, no entanto compreendeu como sendo o trabalho, aquilo que assegura não apenas a sobrevivência do indivíduo, mas a vida da própria espécie. Dessa forma, Arendt (2015) compreende o trabalho como parte do processo biológico do corpo e a partir desta construção, o capitalismo busca se apropriar desse corpo. Conforme Foucault (2015), "Os traços biológicos de uma população se tornam elementos pertinentes para uma gestão econômica e é necessário organizar em volta deles um dispositivo que assegure não apenas sua sujeição, mas o aumento constante de sua utilidade". (FOUCAULT, 2015, p. 304) 
No campo das relações de trabalho, verifica-se a intensificação da precariedade na vida das mulheres. Compreender como a sociedade, ou melhor, como o corpo social se constitui é imprescindível para desvelar os conflitos sociais e desnudar as desumanidades e as subalternidades que produz. Para Foucault (2015), o corpo social não é constituído por um consenso de vontades, mas sim a partir da materialidade do poder se exercendo sobre o corpo das pessoas, e é esse poder investido nos corpos que possibilitou a construção do domínio e da consciência sobre esse próprio corpo.

Segundo Foucault (2015), o poder penetra no corpo e permanece exposto no próprio corpo. Assim, não há como problematizar as questões de gênero sem problematizar as relações de poder. O poder atua na forma de melhor servir ao modo de produção capitalista, hoje representado pelo neoliberalismo, onde os corpos se encontram em constante disputa de forças. Nesta disputa de forças tem prevalecido a constituição de um campo social do trabalho pautado na exploração, na subalternização, na precarização dos corpos dos trabalhadores, maximizado nas questões de gênero.

A CLT previa em seu artigo 394- $\mathrm{A}^{3}$ a garantia de que a empregada gestante ou lactante fosse afastada, enquanto durasse a gestação e a lactação, de quaisquer atividades, operações ou locais insalubres, não fazendo qualquer distinção quanto aos graus de insalubridade, garantindo que o exercício de suas atividades se desse em local sadio. $\mathrm{O}$ artigo 394-A demonstrava a sintonia entre a legislação trabalhista e o direito humano fundamental de proteção à maternidade e à infância, previsto no artigo $6^{04}$ da Constituição Federal.

No entanto, o referido artigo foi brutalmente transmudado pelo legislador reformista, retirando a proteção social da gestante e da lactante submetendo-a a insalubridade no meio laboral. As alterações introduzidas no artigo $394-\mathrm{A}^{5}$ trazem condições variáveis quanto ao trabalho da gestante em condições insalubres, já que, excetuando a insalubridade em grau máximo, a gestante apenas poderá se afastar das demais atividades insalubres se apresentar atestado médico. A lactante por sua vez, terá que apresentar atestado médico para se afastar de ambiente insalubre de qualquer grau.

É importante referir que a Medida Provisória n. 808 altera um pouco a redação do artigo $394-\mathrm{A}^{6}$ alterado pela Lei $13.467 / 17$, apenas invertendo alógica, dizendo que a

\footnotetext{
${ }^{3}$ Art. 394-A. (redação antiga) A empregada gestante ou lactante será afastada, enquanto durar a gestação e a lactação, de quaisquer atividades, operações ou locais insalubres, devendo exercer suas atividades em local salubre. (grifo nosso)

${ }^{4}$ Art. 60 São direitos sociais a educação, a saúde, a alimentação, o trabalho, a moradia, o transporte, o lazer, a segurança, a previdência social, a proteção à maternidade e à infância, a assistência aos desamparados, na forma desta Constituição. (grifo nosso)

${ }^{5}$ Art. 394-A. Sem prejuízo de sua remuneração, nesta incluído o valor do adicional de insalubridade, a empregada deverá ser afastada de: (Redação dada pela Lei no 13.467, de 2017)

I - atividades consideradas insalubres em grau máximo, enquanto durar a gestação;

II - atividades consideradas insalubres em grau médio ou mínimo, quando apresentar atestado de saúde, emitido por médico de confiança da mulher, que recomende o afastamento durante a gestação;

III - atividades consideradas insalubres em qualquer grau, quando apresentar atestado de saúde, emitido por médico de confiança da mulher, que recomende o afastamento durante a lactação.

${ }^{6}$ Art. 394-A. A empregada gestante será afastada, enquanto durar a gestação, de quaisquer atividades, operações ou locais insalubres e exercerá suas atividades em local salubre, excluído, nesse caso, o pagamento de adicional de insalubridade. (Redação dada pela MP 808)
} 
trabalhadora deverá trazer voluntariamente atestado médico se quiser continuar trabalhando em locais insalubres de grau médio e mínimo durante a gestação ou lactação, ou seja, da mesma forma revoga a proibição dada a redação anterior pela Lei 13.287 de maio de 2016 . No entanto, ao que pese as expectativas, a MP 808 não se tornará lei, devendo se extinguir em 28/04/2018.

É sabido, que a reforma como um todo, além de ser considerada o maior ataque as conquistas sociais dos trabalhadores e um retrocesso social sem precedentes, está eivado de inconstitucionalidades, o que se dá exatamente como o artigo 394-A. A Constituição Federal tratou de alçar ao status de direito humano fundamental a proteção à maternidade e à infância no seu artigo $6 .^{\circ}$, que nos termos do caput do artigo $5 .^{\circ}$ é inviolável, dada a supremacia do direito à vida, assim como indispensável a realização do princípio da dignidade da pessoa humana insculpido no inciso III do artigo $1 .^{\circ}$

Ao determinar, em sua redação anterior, que a mulher gestante e lactante seja afastada de ambientes e atividades laborativas insalubres nos períodos de gestação e lactação, o art. 394-A da CLT assumiu caráter de norma de saúde pública, voltada a preservar a saúde da mulher gestante e lactante, do nascituro e da criança lactante contra doenças causadas por agentes de riscos presentes em ambientes e atividades insalubres.

A Constituição ao colocar no mesmo patamar os valores sociais do trabalho e da livre iniciativa (artigo. $1^{\circ}, I V$ ) e ainda conferindo função social à propriedade (artigo $5^{\circ}$, XXII) impõe ao processo de produção, que o trabalhador seja preservado em sua integridade física, psíquica e moral (CR/88, art. $\left.7^{\circ}, \mathrm{XXII}\right)$. Tal direito se encontra revestido de indisponibilidade absoluta, porque nele se projeta a dignidade da pessoa humana, fundamento axiológico nuclear do Estado Democrático de Direito, especialmente quando aplicado à proteção da integridade fisiológica do nascituro e da criança lactante.

A dignidade da pessoa humana e os direitos fundamentais previstos na Constituição Federal de 1988 possuem o condão de impor limites a atuação estatal para que o ente público, em todas as suas dimensões, não venha violar a dignidade pessoal. Mas é certo, que a obrigação estatal vai muito mais além do simples ato de abstenção de violação de direitos fundamentais, é tarefa estatal a atuação permanente no sentido de promover "[...] proteção, promoção e realização concreta de uma vida com dignidade para todos." (Sarlet, 2015, p. 89). Enfim, deve o Estado atuar na elaboração de uma política da dignidade da pessoa humana, capaz de garantir o pleno desenvolvimento da personalidade de cada indivíduo.

[...] sustenta-se, com razão, que a concretização do programa normativo do princípio da dignidade da pessoa humana incumbe aos órgãos estatais, especialmente, contudo, ao legislador, encarregado de edificar uma ordem jurídica que atenda às exigências do princípio. Em outras palavras - aqui considerando a dignidade como tarefa -, o princípio da dignidade da pessoa humana impõe ao Estado, além do dever de respeito e proteção, a obrigação de promover as condições que viabilizem e

§ 20 O exercício de atividades e operações insalubres em grau médio ou mínimo, pela gestante, somente será permitido quando ela, voluntariamente, apresentar atestado de saúde, emitido por médico de sua confiança, do sistema privado ou público de saúde, que autorize a sua permanência no exercício de suas atividades.

§ 3ㅇ A empregada lactante será afastada de atividades e operações consideradas insalubres em qualquer grau quando apresentar atestado de saúde emitido por médico de sua confiança, do sistema privado ou público de saúde, que recomende o afastamento durante a lactação." (NR) 
removam toda sorte de obstáculos que estejam a impedir as pessoas de viverem com dignidade. (SARLET, 2015, p. 90)

Ao que se propôs nesta investigação, é possível verificar a interface entre o relatório aprovado na comissão especial destinada a proferir parecer à proposta de emenda à constituição n. ${ }^{\circ}$ 181-A, o seu impacto nas formas legais de realização de aborto no Brasil e a nova redação do artigo 394-A introduzido pela Lei 13.467/17, afrontando a maternidade, tanto sobre os aspectos relacionados a gestação quanto a lactação, já que possuem amparo constitucional e status de direito humano fundamental, demonstrando desta forma, o papel do discurso jurídico na imposição de um controle biopolítico sobre os corpos das mulheres.

\section{O CORPO COMO UMA CATEGORIA BIOPOLÍTICA}

Investigar o corpo do sujeito não é possível sem que se problematize o corpo como um instituto social. Para Foucault (2015), foi com o surgimento do capitalismo, final do século XVIII, que a ciência médica, chamada de medicina social, começou a preocupar-se com a saúde coletiva da população. Na segunda metade do século XIX, foi colocado em pauta o problema do corpo, da saúde e da força produtiva das pessoas.

[...] o capitalismo, desenvolvendo-se em fins do século XVIII e início do século XIX, socializou um primeiro objetivo que foi o corpo enquanto força de produção, força de trabalho. $\mathrm{O}$ controle da sociedade sobre os indivíduos não se opera simplesmente pela consciência ou pela ideologia, mas começa no corpo, com o corpo. Foi no biológico, no somático, no corporal que, antes de tudo, investiu a sociedade capitalista. O corpo é uma realidade biopolítica. (FOUCAULT, 2015, p. 144)

Nesse momento histórico, a medicina social ampliou-se sobre as classes mais populares, impondo-lhes uma medicina controlada através de uma intervenção médica, que tinha como objetivo, tanto satisfazer as necessidades populares, como colocá-los em permanente isolamento, garantindo assim, um verdadeiro controle médico da população, capaz de torná-la mais apta ao trabalho. Neste momento, o corpo foi investido, política e socialmente como força de trabalho. (Foucault, 2015)

No início do século XX, o corpo passa a ser estudado, investigado, classificado e regulado. Surge como objeto de marcador social e de imposição de diferenciação entre as pessoas, tendo em vista a diversidade de formas, condutas e expressões que facilitam ou dificultam a inclusão dos sujeitos em seus direitos. Dessa forma, os corpos acabam por constituir as identidades de gênero moldadas pelos discursos, dito verdadeiros, de feminilidades e masculinidades.

Foucault (2014) acreditou, em um primeiro momento, na gestão disciplinar dos corpos, na disciplina como técnica de exercício de poder, para posteriormente perceber que passou a operar sob um regime de controles reguladores denominado de biopolítica da população. A partir destas operações de poder, deixa-se de impor um rígido regime disciplinar sobre o corpo do indivíduo para se ocupar mais precisamente com a condição de vida das populações.

Qual é o tipo de investimento do corpo que é necessário e suficiente ao funcionamento de uma sociedade capitalista como a nossa? Eu penso que, do século XVII ao início do século XX, acreditou-se que o investimento pelo poder devia ser 
denso, rígido, constante, meticuloso. Daí esses terríveis regimes disciplinares que se encontram nas escolas, nos hospitais, nas casernas, nas oficinas, nas cidades, nos edifícios, nas famílias... E depois, a partir dos anos 1960, percebeu-se que esse poder tão rígido não era mais tão indispensável quanto se acreditava, que as sociedades industriais podiam se contentar com um poder muito mais tênue sobre o corpo. (FOUCAULT, 2015, p. 237)

O poder se desenvolveu através desses dois polos, regime disciplinar e sociedade de controle. O poder, então, enfrenta o problema dos corpos através de técnicas de administração calculada dos corpos dos indivíduos e, mais amplamente, pela gestão meticulosa da vida das pessoas. Diversas técnicas foram elaboradas para impor a sujeição dos corpos e o controle das populações. O interesse primordial do poder, a partir de então, passou a ser a utilização em grande escala dos corpos assujeitados, retirando deles o maior rendimento possível.

Nesse conjunto de problemas, os "corpos" - corpo dos indivíduos e corpo das
populações - surgem como portadores de novas variáveis: não mais simplesmente
raros ou numerosos, submissos ou renitentes, ricos ou pobres, válidos ou inválidos,
vigorosos ou fracos e sim mais ou menos utilizáveis, mais ou menos suscetíveis de
investimentos rentáveis, tendo maior ou menor chance de sobrevivência, de morte
ou de doença, sendo mais ou menos capazes de aprendizagem eficaz. (FOUCAULT,
2015 , p. 303-304)

A organização do corpo social pelas regras do biopoder passa a ter o biológico refletido sobre o político. Conforme Foucault (2015), as características biológicas da população se constituem os elementos indispensáveis para uma gestão econômica dos sujeitos. Para tanto, vários dispositivos são criados para aumentar a utilidade dos corpos, dentre eles, está a construção da identidade dos sujeitos a partir de uma lógica binária, sobre a qual são estabelecidos papéis naturalizados para homens e mulheres.

As relações sociais construídas a partir dos mecanismos de produção capitalista investiram no aumento da produtividade e na maior utilidade dos corpos da massa trabalhadora. Estes mecanismos proporcionaram maior lucro e, consequentemente, maior acumulação de capital. O produto desta acumulação é uma realidade de segregação e de hierarquização social, pautada em relações de dominação, consolidando a hegemonia do capital. A partir daí, torna-se importante compreender de que forma o biopoder distribui de forma diferenciada, a segregação e a hierarquização social entre os corpos dos homens e das mulheres trabalhadoras.

Dentro dos diversos campos sociais proliferam tecnologias políticas que passam a investir sobre os corpos, sobre a saúde, sobre a maneira de se alimentar e de morar das pessoas, sobre suas condições de vida e sobre todos os demais espaços destinados a sua existência. Tecnologias incutidas de dispositivos de saber e de poder modelam os papeis que cabem a mulheres e a homens. Dentre as várias relações de poder que produzem as identidades de gênero das mulheres, o dever de cuidado, culturalmente instituído como sendo o papel fundamental da mulher, é determinante na construção das relações de poder que permeiam as relações de trabalho.

No entanto, impossível analisar a construção cultural das identidades de gênero das mulheres, sem investigar a importância assumida pela norma legal nesta realidade biopolítica. O sistema jurídico da lei produz e reproduz os sistemas de exclusão e de subordinação das mulheres nas relações sociais do mundo do trabalho, distribuindo entre a grande massa de 
trabalhadores, um domínio diferenciado de valor e de utilidade. Neste caso, o sexo tem grande importância, assumindo o pano de fundo de uma disputa política pela própria vida. Para Foucault (2014):

\begin{abstract}
Não quero dizer que a lei se apague ou que as instituições de justiça tendam a desaparecer; mas que a lei funciona cada vez mais como norma, e que a instituição judiciária se integra cada vez mais num contínuo de aparelhos (médicos, administrativos, etc.) cujas funções são sobretudo reguladoras. Uma sociedade normalizadora é o efeito histórico de uma tecnologia de poder centrada na vida. (FOUCAULT, 2014, p. 156)
\end{abstract}

Para Foucault (2014), a teoria geral sobre o sexo consolidou determinadas funções inerentes ao dispositivo da sexualidade. Dentre elas, está a construção de uma ideia de unidade artificial entre elementos anatômicos, funções biológicas, sensações e prazeres que culminam na construção de uma linha de contato entre um saber sobre a sexualidade e o saber científico. Une-se assim o saber sobre a sexualidade humana com a sua utilidade para as ciências biológicas da reprodução, papel destinado às mulheres que estabelece uma normalidade. Dentre os dispositivos de poder que regulam o corpo social, está o da sexualidade à disciplinar o corpo da mulher como destinado à reprodução e ao cuidado da prole.

Segundo o autor, é pelo sexo que todas as pessoas terão acesso a sua inteligibilidade, à totalidade do seu corpo e, principalmente, a sua identidade. A partir do sexo, o poder busca sujeitar os corpos que, a partir desta sujeição, constituirão sua identidade. Quanto às mulheres, estas somente terão acesso à inteligibilidade de seu corpo, caso cumpram rigorosamente com as normas definidoras desta inteligibilidade: cumprir seu papel de reprodução e de cuidado com as pessoas. Para tanto, devem ser retiradas todas as formas de autonomia sobre seus corpos, assim pode-se dizer que o parecer da PEC 181-A faz parte de uma estratégia de dominação.

A construção discursiva do papel do corpo da mulher, como aquele destinado à reprodução e ao cuidado da prole, está diretamente relacionada com a forma de organização social das relações de trabalho, que vê no corpo da mulher a possibilidade de consolidação dos meios de produção capitalista. O capitalismo necessita de uma massa de mão de obra útil e eficaz para a consolidação e expansão de suas forças produtivas e, consequentemente, para uma maior acumulação do capital. Neste sentido, a desconstrução do padrão de identidade que oprime e subjuga as mulheres, opera-se na subversão de toda e qualquer ordem normativa imposta sobre seus corpos, seus prazeres, seus sentimentos.

As relações de poder utilizam o discurso jurídico para impor diversas formas de subjugação e de dominação dos sujeitos, especialmente no que se refere a autonomia do próprio corpo e às relações de trabalho das mulheres. Este discurso não se limita aos discursos formulados pela fábrica ${ }^{7}$, mas sim, àqueles que vêm da fábrica, (FOUCAULT, 2015). Ao analisar as relações de trabalho compreende-se que a forma como as decisões, os regulamentos, os discursos ditos e não ditos, suas táticas, suas estratégias, não são de ninguém e ao mesmo tempo são de todo mundo, já que não emanam de um sujeito específico, mas de

\footnotetext{
${ }^{7}$ Aqui o autor se refere à fábrica como o local simbólico para designar todo e qualquer local onde se desenvolvem as relações sociais do trabalho. 
todas as estruturas que compõem esse campo social, garantindo o seu funcionamento e a sua permanência como instituição.

O discurso jurídico, assim como o campo social do trabalho produzem e reproduzem relações pautadas em violência sistêmica contra as mulheres, atingindo diferentes mulheres de diferentes formas, mas atingindo todas as mulheres. A norma referente à feminilidade, pautada em questões como sexualidade, violência, direitos reprodutivos, entre outros, são muitas vezes, frustradas por tabus morais. Estes tabus deslocam para o campo da esfera pessoal, questões tão afetas à pauta de justiça de gênero.

\section{CONSIDERAÇÕES FINAIS}

Para concluir, tem-se que a subjugação das mulheres ocorre sob a forma de controle de seus corpos. Desta maneira, pode-se dizer que os corpos das mulheres estão no centro de suas demandas sociais e políticas. Questões de gênero são problematizadas em todos os corpos, no entanto, alguns corpos são mais marcados pela violência do que outros. As pautas por justiça de gênero devem partir dessa premissa, já que a precariedade é uma condição generalizada e distribuída de forma diferencial na vida das pessoas. Ademais, cumpre ainda referir, que esses corpos encontram-se em constante disputa, haja vista que o poder os penetrou, neles está exposto, daí a existência de uma constante correlação de forças. A materialidade do poder exerce-se sobre o próprio corpo dos indivíduos.

Os corpos são construídos discursivamente através de um saber científico dito verdadeiro, organizado no interior da nossa sociedade. Faz-se necessário (des)construir os efeitos desse saber/poder centralizador, ligado às instituições e ao seu funcionamento. Tratase, segundo Foucault (2015), de uma batalha dos saberes contra os efeitos de poder do discurso científico, do qual não escapa o discurso jurídico.

Conclui-se que os efeitos do poder se ligam ao saber de todas as formas e em todos os lugares, enraizados nos mais diversos campos sociais. Questiona-se, portanto, quais relações de poder constroem os saberes jurídicos e, inversamente, quais relações de poder se constituem através do discurso jurídico dito verdadeiro, produzindo e reproduzindo desigualdades profundas no que tange às mulheres e em especial à mulheres trabalhadoras.

Ademais, a legitimação das estruturas do funcionamento legal da legislação trabalhista, de perpetuação de ausências de direitos plenos às trabalhadoras, é a demonstração efetiva do que Spyvak (2010) denomina de violência epistêmica caracterizada por um projeto legal neocolonialista de ausência de representação legal e política do sujeito subalterno, uma vez que esse sujeito subalterno se encontra impossibilitado de articular um discurso de resistência que esteja fora dos discursos hegemônicos.

Para Spyvak (2010), se o discurso do subalterno é eliminado, suprimido, o da mulher subalterna encontra-se em uma posição ainda mais periférica, dado os problemas relacionados às questões de gênero, sendo colocado, dentro do contexto da produção colonial dos discursos, numa posição ainda mais profunda de obscuridade.

É mais uma questão de que, apesar de ambos serem objetos da historiografia colonialista e sujeitos da insurgência, a construção ideológica de gênero mantém a dominação masculina. Se, no contexto da produção colonial, o sujeito subalterno 
não tem história e não pode falar, o sujeito subalterno feminino está ainda mais profundamente na obscuridade. (SPYVAK, 2010, p. 66-67)

Quando se fala em neocolonialismo, está também se referindo a problemática da divisão internacional do trabalho contemporâneo, colocando de um lado, um grupo de países, em sua maioria de primeiro mundo, aptos a investir seu capital em países de terceiro mundo, que reconhecidamente possuem um campo fértil para esse tipo de investimentos, dada a sua característica consumista e da existência de uma vasta mão de obra, mal protegida e mutável. Este espaço foi então extremamente propício para a implementação de uma reforma trabalhista precarizante e subalternizante.

Pode-se dizer, que se trata de um verdadeiro processo de colonização da mão de obra de terceiro mundo. Desta forma, a autora, critica as teorias de divisão internacional do trabalho ao reduzirem o problema da mão de obra ao barato ou ao caro, posto que entende, que a subalternidade dos trabalhadores se encontra na ausência de proteção legal, situação esta, que se coaduna perfeitamente à reforma trabalhista implementada por um governo sem qualquer legitimidade, ou seja, "O trabalho humano não é intrinsecamente "barato" ou "caro". É assegurado por uma ausência de leis de trabalho (ou sua execução discriminatória), [...]." (SPYVAK, 2010, p. 68)

Neste contexto, o presente trabalho pode ainda ser problematizado a partir da concepção de subalternidade de Spyvak, compreendendo que o sujeito subalterno é efeito do "discurso dominante", o que propicia o questionamento acerca do discurso que é sempre "sobre" a mulher e, no caso da mulher trabalhadora é mais intenso, pois concentra-se na construções de papéis do feminino e do masculino, segundo o qual o papel de cuidado é destinado à mulher e a essa mulher que cuida da vida do outro, a pena é o silêncio. Assim, é possível afirmar, dentro de uma perspectiva spivakiana, que a mulher trabalhadora representa o sujeito subalterno feminino, a qual se encontra em uma condição mais intensa de obscuridade, o que favorece a sua perpetuação.

Pode-se dizer, que a discussão acerca do mundo do trabalho no Brasil, está inserido dentro do que Butler chama de problemas de gênero. Para Butler (2014), os sistemas jurídicos de poder produzem os sujeitos, limitando a vida política dos indivíduos ligados a esta estrutura, ou seja, a formação jurídica da linguagem e da política que representa as mulheres como sujeito é formado através de um discurso que em tese, deveria facilitar a "emancipação" das mulheres, no entanto, se transforma em um sistema que produz esse sujeito dentro de padrões de dominação, contribuindo para o fracasso da tão desejada emancipação.

Não basta inquirir como as mulheres podem se fazer representar mais plenamente na linguagem e na política. A crítica feminista também deve compreender como a categoria das "mulheres", o sujeito do feminismo, é reproduzida e reprimida pelas mesmas estruturas de poder por intermédio das quais busca-se a emancipação. (BUTLER, 2014, p. 19)

Para Butler (2014), a emancipação das mulheres somente ocorrerá com práticas subversivas que questionem as relações de poder, que discursivamente constroem as relações de gênero dentro de um padrão binário, onde as categorias homem/mulher, masculino/feminino são colocadas em oposição, constituindo relações sociais hierarquizadas, onde a mulher se constitui em posição de inferioridade em ralação ao homem e a elas, são relegadas as condições mais precarizadas de vida e de trabalho. 
Nesse contexto, a partir da proposta do presente trabalho, qual seja, de analisar a interface entre o relatório da comissão especial destinada a dar parecer acerca da PEC 181-A, que propõe além da ampliação da licença maternidade para o ocaso de nascimento de prematuros, propõe a alteração do inciso III do artigo $1^{\circ}$ e o caput do artigo $5^{\circ}$ da Constituição Federal, acrescentando ao texto constitucional que tanto a vida quanto a dignidade da pessoa humana serão garantidas desde a concepção, interferindo de modo brutal na interpretação de todas as normas atinentes as modalidades de abortos legais no Brasil e a nova redação do artigo 394-A da CLT, que retira a proteção anteriormente dada a maternidade, desde a gestação até a lactação, demonstra claramente o poder construindo saberes jurídicos e inversamente estes discursos dito verdadeiros construindo relações de poder de subalternidade para as mulheres trabalhadoras.

A problematização destes ataques brutais aos direitos, tanto reprodutivos como trabalhistas das mulheres, ambos com proteção nos direitos fundamentais da carta política brasileira, escancaram a invisibilidade do sujeito subalternizado da mulher trabalhadora, para a qual não existe espaço de fala, vez que ausentes os espaços de representação política desse sujeito. Para Lagarde (2015), a capacidade de lutar por reconhecimento político e de implementação de mudanças nas relações sociais relacionadas a vida, tanto reprodutiva como laborativa das mulheres, é a medida mais importante para impor transformações, só que para isso, segundo a autora é indispensável a sensibilidade intelectual e afetiva para se compreender as necessidades das pessoas e dos grupos a partir de uma (re)significação política de gênero.

Ainda sobre a questão do reconhecimento, segundo Butler (2015), para que o sujeito seja reconhecido como sujeito, este deve ter sido constituído por normas que facilitem este reconhecimento, caso contrário teremos sujeitos que não serão reconhecíveis como sujeitos e provavelmente nunca serão reconhecidas como vidas. Dessa maneira, a capacidade de apreender uma vida depende em muito, daquilo que já foi dito, de que o sujeito tenha sido constituído de acordo com as normas que a caracterizam como uma vida, produzindo ainda, um problema ético no que se refere a capacidade de definir o que será reconhecido e o que será, consequentemente passível de ser protegido contra a violência.

A conclusão de que não há vida como não precária, poderia nos levar a pensar que essa condição compartilhada de precariedade conduziria a um reconhecimento recíproco desta condição produzindo um sentimento de solidariedade, no entanto, o resultado decorrente desta condição é justamente o contrário, qual seja, a de "uma exploração específica de populaçõesalvo, de vidas que não são exatamente vidas, que são consideradas "destrutíveis" e "não passíveis de luto". (BUTLER, 2015, p. 53)

Portanto, dizer que a vida é precária traz como compromisso a manutenção dessa vida, o que somente será possível com a implementação de condições sociais e políticas que garantam a existência dessa vida, posto que, “[...] não pode haver nenhuma persistência na vida sem pelo menos algumas condições que tornem uma vida vivível." (BUTLER, 2015, p. 40). Assim, a existência destas vidas, somente terão sentido com o reconhecimento à autonomia da mulher, tanto em relação ao seu corpo e seus direitos reprodutivos, como com o reconhecimento do direito de proteção irrestrita à maternidade, desde a gestação até a lactação, como direitos humanos fundamentais e inalienáveis da mulher. Qualquer dispositivo que negue esse reconhecimento se caracteriza como violência de gênero. 
Para concluir, segundo Butler (2015), deve-se ter responsabilidade moral e ética para construir uma crítica social que busque a criação de condições sociais e econômicas pautadas em sentimentos de afetividade, os quais possibilitarão desenvolver sentimentos de comoção perante a violência e as mais diversas formas de violação da vida. Quando o outro se comove com o sofrimento e com a condição maximizada da precariedade da vida do outro, este sujeito passa a reconhecido como uma vida a ser vivida de forma a minimizar a sua precariedade.

\section{REFERÊNCIAS}

BRASIL. Códigos 4 em 1 Saraiva: CLT, CPC, Legislação Previdenciária / obra coletiva de autoria da Editora Saraiva com a colaboração de Luiz Roberto Curia, Lívia Céspedes e Fabiana Dias da Rocha. - 11 ${ }^{\mathrm{a}}$ ed. - São Paulo: Saraiva, 2016.

BRASIL, Projeto de Emenda à Constituição n. ${ }^{\circ}$ 181-A. Disponível em http://www.camara.gov.br/proposicoesWeb/prop mostrarintegra?codteor=1586817\&filename $=\mathrm{SBT}+1+\mathrm{PEC} 18115+\% 3 \mathrm{D} \% 3 \mathrm{E}+\mathrm{PEC}+181 / 2015$ acessado em 08/03/2018.

BRASIL, Constituição da República Federativa do Brasil. Disponível em http://www.planalto.gov.br/ccivil_03/constituicao/constituicaocompilado.htm acessado em 08/03/2018.

BUTLER, Judith. Problemas de gênero: Feminismo e subversão da identidade. $7^{\mathrm{a}} \mathrm{ed}$. Rio de Janeiro: Civilização Brasileira, 2014.

BUTLER, Judith. Quadros de Guerra - quando a vida é passível de luto? $1^{\text {a }}$ ed. Rio de Janeiro: Civilização Brasileira, 2015.

DELGADO, Mauricio Godinho e DELGADO, Gabriela Neves. O novo manual do trabalho doméstico - São Paulo : LTr, 2016.

ESCRIVÃO FILHO, Antônio; SOUSA JUNIOR, José Geraldo de. Para um debate teóricoconceitual e político sobre os direitos humanos - Belo Horizonte: Editora D’Plácido, 2016.

FOUCAULT, Michel. História da Sexualidade 1: A vontade de saber. - São Paulo : Paz e Terra, 2014.

FOUCAULT, Michel. Microfísica do Poder. - 2ªed. Rio de Janeiro: Paz e Terra, 2015.

GARCIA, Gustavo Filipe Barbosa. Manual de Direito do Trabalho - $7^{\text {a }}$ ed. - Rio de Janeiro: Forense; São Paulo: Método, 2015.

LAGARDE, Marcela. Claves feministas para mis sociais de la vida. - Ciudad Autónoma de Buenos Aires: Diego Pérez Roig, 2015.

MAIOR, Jorge Luiz Souto; SEVERO, Valdete Souto. (coordenadores) Resistência: aportes teóricos contra o retrocesso trabalhista - São Paulo: Expressão Popular, 2017

MARTINEZ, Luciano. Reforma Trabalhista: entenda o que mudou $-2^{a}$ ed. - São Paulo: Saraiva, 2018. 
MARTINS, Sérgio Pinto. Direito do Trabalho - 30 ed. - São Paulo: Atlas, 2013.

MORAES, Maria Celina Bondin. O conceito da dignidade humana: substrato axiológico e conteúdo normativo. In. SARLET, Ingo Wolfgang, org. Constituição, direitos fundamentais e direito privado. 2. ed., rev. e ampl. Porto Alegre: Livraria do Advogado, 2006. p. 107-149.

NERY JUNIOR, Nelson e NERY Rosa Maria de Andrade. Constituição Federal Comentada e legislação constitucional. - São Paulo: Editora Revistas dos Tribunais, 2006.

OIT. Convenção n. ${ }^{0} \mathbf{1 0 3}$ - Proteção à maternidade. Disponível em: <http://www.oitbrasil.org.br/node/524.><acesso 08/03/2018>.

RESENDE, Ricardo. Direito do Trabalho esquematizado - $3^{\mathrm{a}}$ ed. - Rio de Janeiro: Forense; São Paulo: Método, 2013.

RODRIGUES JR, Edson Beas. (organizador) Convenções da OIT e outros instrumentos de direito internacional público e privado relevantes ao direito do trabalho. $3^{\mathrm{a}} \mathrm{ed}$. - São Paulo: LTr, 2017.

SARLET, Ingo Wolfgang. Dignidade (da Pessoa) Humana e Direitos Fundamentais de 1988 -9 ${ }^{\text {a }}$ ed. - Porto Alegre: Livraria do Advogado, 2012.

SARLET, Ingo Wolfgang; MELLO FILHO, Luiz Philippe Vieira de e FRAZÃO, Ana de Oliveira. (coordenadores) Diálogos entre o direito do trabalho e o direito constitucional: estudos em homenagem a Rosa Maria Weber - São Paulo: Saraiva, 2014.

SPYVAK, Gayatri Chakravorty. Pode o Subalterno Falar? - Belo Horizonte: Editora UFMG, 2010. 